\title{
The antiplasmodial and spleen protective role of crude Indigofera oblongifolia leaf extract traditionally used in the treatment of malaria in Saudi Arabia
}

\author{
Mohamed A Dkhil ${ }^{1,2}$ \\ Mahmoud Y Lubbad ${ }^{1,3}$ \\ Esam M Al-Shaebil \\ Denis Delic ${ }^{4}$ \\ Saleh Al-Quraishy' \\ 'Department of Zoology, College \\ of Science, King Saud University, \\ Riyadh, Saudi Arabia; ${ }^{2}$ Department \\ of Zoology and Entomology, Faculty \\ of Science, Helwan University, \\ Helwan, Egypt; ${ }^{3}$ General Directorate \\ of Environmental and Occupational \\ Health, Public Health Agency, Ministry \\ of Health, Riyadh, Saudi Arabia; \\ ${ }^{4}$ Boehringer-Ingelheim Pharma, \\ Biberach, Germany
}

\author{
This article was published in the following Dove Press journal: \\ Drug Design, Development and Therapy \\ 25 November 2015 \\ Number of times this article has been viewed
}

Abstract: Malaria is one of the most serious natural hazards faced by human society. Although plant leaves of Indigofera oblongifolia have been used for the treatment of malaria in Saudi Arabian society, there is no laboratory-based evidence for the effectiveness and safety of the plant. This study therefore was designed to investigate the antimalarial and spleen protective activity of I. oblongifolia leaf extract (IOLE) in mice. Three doses (100, 200 and $300 \mathrm{mg} / \mathrm{kg}$ ) of IOLE were used to treat mice infected with Plasmodium chabaudi-parasitized erythrocytes. The suppressive effect produced by the $100 \mathrm{mg} / \mathrm{kg}$ dose on parasitemia was highly significant compared to the infected nontreated group. This dose was also able to repair the change in the thickness of the mice spleen and significantly lower the number of apoptotic cells in the spleen. Moreover, I. oblongifolia also altered gene expression in the infected spleen. On day 7 postinfection, the mRNA expression of six genes - with immune response functions - was upregulated by more than twofold, while that of 24 other genes was downregulated. Among the differentially up- and downregulated genes under the effect of IOLE, we quantified the expression of Ccl8, Saa3, $C d 209 a$, and $C d 209 b$ mRNAs. The expression data, determined by microarrays, were largely consistent with the expression analyses we performed with several arbitrarily selected genes using quantitative polymerase chain reaction (PCR). Based on our results, I. oblongifolia exhibits antimalarial activity and could protect the spleen from $P$. chabaudi-induced injury.

Keywords: spleen, malaria, Indigofera oblongifolia, apoptosis, microarray

\section{Introduction}

Malaria is a life-threatening disease caused by parasites that are transmitted to people through the bites of infected mosquitoes. ${ }^{1}$ According to the latest estimates by the World Health Organization, there were approximately 198 million cases of malaria in 2013 and an estimated 584,000 deaths. ${ }^{2}$

Although malaria can be treated with numerous commercially available antimalarial drugs, drug resistance is a continual problem. Indeed, resistance against currently used drugs is increasingly being reported. ${ }^{3}$ Parasite resistance results in a delayed or incomplete clearance of parasites from the patient's blood when the person is being treated with an antimalarial agent. ${ }^{4}$ Novel agents possessing antimalarial activity, and that are safe for use in humans, are therefore urgently required.

People have used medicinal plants for the treatment of malaria since ancient times, and such plants remain promising sources for identifying candidates for novel anti-malaria agents. ${ }^{5,6}$ These products do not necessarily target only the plasmodium, but may also show organ-protective properties in the plasmodium-infected hosts. ${ }^{7,8}$
Correspondence: Mohamed A Dkhi Department of Zoology, College of Science, King Saud University, PO Box 2455, Riyadh II45I, Saudi Arabia Tel +966 I| 4675754 Fax +966 II 46785 I4 Emailmohameddkhil@yahoo.com 
For example, our recent work has showed that pomegranate peel extract and berberine could be used as antimalarial and hepatoprotective agents. ${ }^{7}$

In the case of Saudi Arabia, Indigofera oblongifolia (family Fabaceae) is cultivated in areas with a high prevalence of malaria, such as Jazan and Nagran. ${ }^{5}$ Despite the fact that this plant is used informally for the treatment of malaria in Saudi Arabian society, there is no laboratorybased evidence for its effectiveness or safety. This study was therefore designed to investigate the antimalarial and spleen protective activity of $I$. oblongifolia leaf extract (IOLE) in a murine model.

\section{Materials and methods}

\section{Preparation of $I$. oblongifolia leaf extract}

The leaves of I. oblongifolia were collected from Jazan, Saudi Arabia. The plant was identified by Dr Pandalayil (Department of Botany, College of Science, King Saud University). The leaves were air dried and then ground into a powder. The constituents of the powdered leaves were extracted with $70 \%$ methanol. $^{9}$

\section{Animals}

Nine- to twelve-week-old female C57BL/6 mice were obtained from the animal facility of the research center at King Faisal Specialist Hospital in Riyadh, Saudi Arabia. The mice were bred under specified pathogen-free conditions and fed a standard diet and water ad libitum. The experiments were approved by the state authorities at King Saud University for the project number PRG-02, and followed Saudi Arabian rules on animal protection.

\section{Mice infection}

Following the method of Wunderlich et al, ${ }^{10}$ female mice were inoculated at weekly intervals with blood-stage infections of Plasmodium chabaudi by intraperitoneally injecting them with $1 \times 10^{6} P$. chabaudi-parasitized erythrocytes. Parasitemia was detected in Giemsa-stained smears from tail blood. Cell numbers were counted in a Neubauer chamber.

\section{Experimental design}

Animals were divided into five groups with ten mice in each group. The first group, with uninfected mice, served as a vehicle control. This group was gavaged only with $100 \mu \mathrm{L}$ distilled water. The second, third, fourth, and fifth groups were intraperitoneally infected with $1 \times 10^{6} P$. chabaudiinfected erythrocytes, as described earlier. Then, after
60 minutes, mice of the third, fourth, and fifth groups were gavaged with $100 \mu \mathrm{L}$ of IOLE at a dosage of 100, 200, and $300 \mathrm{mg} / \mathrm{kg}$ body weight of IOLE, respectively, once daily for 7 days. The average percentage of suppression by IOLE was calculated using the formula:

$$
\% \text { suppression }=\frac{\begin{array}{c}
\text { Parasitemia in negative control }- \\
\text { parasitemia in test group }
\end{array}}{\text { Parasitemia in negative control }} \times 100
$$

\section{Preparation of spleen tissue}

Both noninfected and $P$. chabaudi-infected spleens were aseptically removed from mice on day 7 pi. Half of the spleen was fixed in $10 \%$ neutral buffered formalin for histological and immune histochemical investigations, and the other half was kept in RNAlater storage solution (Qiagen, Hilden, Germany) for the molecular study.

\section{Spleen index and capsule thickness}

The spleen index was determined as the ratio of the weight of the spleen to the weight of the mouse. To evaluate the spleen capsule thickness, the paraffin sections of the spleen were prepared according to standard protocols. ${ }^{11}$ Sections with a thickness of $5 \mu \mathrm{m}$ were stained with hematoxylin and eosin. Capsule thickness was determined in five different mice spleen sections from each group.

\section{TUNEL apoptosis detection}

Terminal deoxynucleotidyl-transferase-mediated dUTP nick end labeling assay (TUNEL) staining was performed using a TUNEL Apoptosis Detection Kit (GenScript, Piscataway, NJ, USA) according to the manufacturer's protocol. Briefly, sections of paraffin-embedded spleens were deparaffinized and then rehydrated in graded ethanol solutions before digestion with proteinase K. Slides were mounted with 4',6-diamidino-2-phenylindole. Nuclei of the apoptotic cells appeared dark brown. Sections were counterstained with hematoxylin. The number of TUNEL-positive cells was counted in ten different areas per section.

\section{RNA isolation and quality testing}

Total RNA was isolated with TRIzol (Qiagen). The quality and integrity of RNA were determined using the Agilent RNA 6000 Nano Kit on the Agilent 2100 Bioanalyzer (Agilent Technologies, Santa Clara, CA, USA). RNA was quantified by measuring the absorbance at $260 \mathrm{~nm}$ on the ND-1000 spectrophotometer (NanoDrop Technologies, Wilmington, DE, USA). ${ }^{12}$ 


\section{Labeling of RNA}

Equal amounts of RNA prepared from individual spleen tissues of three mice were pooled. Labeling was performed as detailed in the protocol for the One-Color MicroarrayBased Gene Expression Analysis (version 5.5, part number G4140-90050). Briefly, $1 \mu \mathrm{g}$ of total RNA was used for amplification and labeling using the Agilent Low RNA Input Linear Amp Kit (Agilent Technologies) in the presence of cyanine 3-CTP and cyanine 5-CTP (PerkinElmer, Waltham, MA, USA). Yields of complementary RNA (cRNA) and the dye-incorporation rate were measured with the ND-1000 spectrophotometer (NanoDrop Technologies).

\section{Hybridization of Whole Mouse Genome Oligo Microarray}

The hybridization procedure was performed according to the One-Color Microarray-Based Gene Expression Analysis protocol (version 5.5, part number G4140-90050) using the Agilent Gene Expression Hybridization Kit (Agilent Technologies). Briefly, $825 \mathrm{ng}$ of the corresponding $\mathrm{Cy} 3-$ and Cy5-labeled cRNA was combined and hybridized overnight at $65^{\circ} \mathrm{C}$ to Agilent Whole Mouse Genome Oligo Microarrays $8 \times 60 \mathrm{~K}$ using the hybridization chamber and oven recommended by Agilent. The used microarrays contained 55,681 gene-specific oligo spots including 39,430 Entrez Gene RNAs and 16,251 lincRNAs. After hybridization, the microarrays were washed once with $6 \times$ SSPE buffer containing $0.005 \% \mathrm{~N}$-lauroylsarcosine for 1 minute at room temperature, followed by a second wash with preheated $0.06 \times$ SSPE buffer at $37^{\circ} \mathrm{C}$ containing $0.005 \% \mathrm{~N}$-lauroylsarcosine for 1 minute. Acetonitrile was used for the last washing step for 30 seconds.

\section{Scanning and data analysis}

Fluorescence signals of the hybridized microarrays were monitored using Agilent's Microarray Scanner System G2505B and the Scan Control Software (Agilent Technologies). The Agilent Feature Extraction Software (FES) version 10.2.1.3 was used to read out and process the microarray image files. For the determination of differential gene expression, the FES derived output data files were further analyzed using the Rosetta Resolver ${ }^{\circledR}$ Gene Expression Data Analysis System (Rosetta Biosoftware, Seattle, WA, USA). The local signal of each spot was measured inside a $300 \mu \mathrm{m}$ diameter circle. The local background was determined within $40 \mu \mathrm{m}$ wide rings approximately $40 \mu \mathrm{m}$ distant from the signal. Then, local background was subtracted from the local signal intensity to calculate the net signal intensity and the ratio of $\mathrm{Cy} 5$ to $\mathrm{Cy} 3$. The ratios were normalized to the median of all ratios, considering only those spots with fluorescence intensities three times larger than that of the control herring sperm DNA and spotting buffer negative controls. The values represent the means of four single spots and standard deviations. Cutoff was chosen at $>$ twofold expression with $P<0.01$.

\section{Quantitative PCR}

All RNA samples were treated with DNase (Applied Biosystems, Darmstadt, Germany) for at least 1 hour and were then converted into cRNA using the Reverse Transcription Kit following the manufacturer's protocol (Qiagen). Quantitative real-time PCR (RT-qPCR) was performed using the ABI Prism $7500 \mathrm{HT}$ sequence detection system (Applied Biosystems) with SYBR green PCR master mix from Qiagen. Genes were investigated by encoding the mRNAs for the following proteins: serum amyloid a3 (SAA3) (Mm_Saa3_1_SG), chemokine (C-C motif) ligand 8 (CCL8) (Mm_Ccl8_1_SG), cluster of designation 209a (CD209A) (Mm_Cd209a_1_SG), cluster of designation 209b (CD209B) (Mm_Cd209b_1_SG), and glyceraldehyd-3-phosphat-dehydrogenase (GAPDH) (Mm_Gapdh_1_SG). All primers used for RT-qPCR were obtained commercially from Qiagen. PCRs were conducted as follows: 2 minutes at $50^{\circ} \mathrm{C}$ to activate uracil-N-glycosylase (UNG); $95^{\circ} \mathrm{C}$ for 10 minutes to deactivate $\mathrm{UNG}$; and 40 cycles at $94^{\circ} \mathrm{C}$ for 15 seconds, $60^{\circ} \mathrm{C}$ for 35 seconds, and $72^{\circ} \mathrm{C}$ for 30 seconds. Reaction specificity was checked by performing dissociation curves after PCR. For quantification, mRNA levels were normalized to those of GAPDH. The threshold cycle $\left(\mathrm{C}_{\mathrm{T}}\right)$ value was the cycle number, selected from the logarithmic phase of the PCR curve, in which an increase in fluorescence above background could be detected. $\Delta \mathrm{C}_{\mathrm{T}}$ was determined by subtracting the $\mathrm{C}_{\mathrm{T}}$ of GAPDH from the $\mathrm{C}_{\mathrm{T}}$ of the target. The fold change of mRNA expression was determined using the $2-\Delta \Delta \mathrm{CT}$ method.

\section{Statistical analysis}

One-way ANOVA was carried out, and the statistical comparisons among the groups were performed with Duncan's $t$-test using a statistical package program (SPSS version 17.0). $P \leq 0.05$ was considered as significant for all the statistical analyses in this study.

\section{Results}

The in vivo antiplasmodial activity study revealed that the methanolic extract of I. oblongifolia produced suppression of parasitemia in a dose-dependent manner when compared 
Table I Indigofera oblongifolia-induced suppression of parasitemia in mice infected with Plasmodium chabaudi on day $7 \mathrm{pi}$

\begin{tabular}{|c|c|c|c|}
\hline Group & $\begin{array}{l}\text { Dose of } \\
\text { IOLE } \\
(\mathrm{mg} / \mathrm{kg})\end{array}$ & $\begin{array}{l}\text { Parasitemia } \\
\text { (\%) }\end{array}$ & $\begin{array}{l}\text { Suppression } \\
\text { of parasitemia } \\
(\%)\end{array}$ \\
\hline Infected (- IOLE) & - & $38 \pm 6$ & - \\
\hline Infected (+ IOLE-100) & 100 & $12 \pm 3 *$ & $68.4 \pm 8$ \\
\hline Infected (+ IOLE-200) & 200 & $34 \pm 8$ & $10.5 \pm 3$ \\
\hline Infected (+ IOLE-300) & 300 & $22 \pm 5 *$ & $42.1 \pm 6$ \\
\hline
\end{tabular}

to the negative control in this study. The suppression was $68.4 \% \pm 8 \%, 10.5 \% \pm 3 \%$, and $42.1 \% \pm 6 \%$ for 100,200 , and $300 \mathrm{mg} / \mathrm{kg}$ doses, respectively (Table 1). The suppressive effect produced by the dose $100 \mathrm{mg} / \mathrm{kg}$ was highly significant $(P<0.001)$ compared with the negative control.

Splenomegaly in mice was shown at day 7 pi with $P$. chabaudi (Figure 1). This was indicated by the determination of the splenic index (ratio of spleen weight to the mice weight) (Figure 1). IOLE was able to reduce the increased spleen index (Figure 1). Also, the capsule of the mice spleen infected with $P$. chabaudi-infected erythrocytes decreased in thickness compared to that of the control spleen (Figure 2). Treatment of the infected mice with $100 \mathrm{mg}$ IOLE/ $\mathrm{kg}$ was able to reverse this change in spleen thickness (Figure 3), while the other two doses (200 and $300 \mathrm{mg}$ IOLE/kg) did not show significant improvement in the spleen thickness.

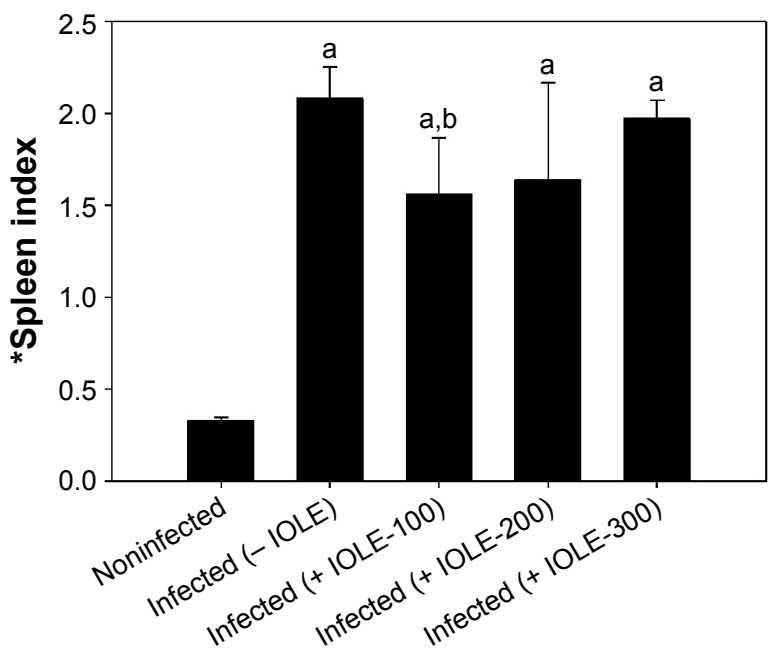

Figure I Changes in spleen index of uninfected, Plasmodiun chabaudi-infected, and infected I. oblongifolia treated mice on day 7 pi.

Notes: Values are means \pm SD. a Significant against noninfected group at $P \leq 0.05$. 'Significant against infected ( - IOLE) group at $P \leq 0.05$. *Ratio of spleen weight in $\mathrm{mg} /$ mouse to body weight in $\mathrm{g} /$ mouse.

Abbreviations: pi, postinfection; SD, standard deviation; IOLE, I. oblongifolia leaf extract.
A higher number of TUNEL-positive cells were shown in spleen sections of mice infected with $P$. chabaudi-parasitized erythrocytes on day 7 pi (Figures 4 and 5). I. oblongifolia was able to reduce the number of TUNEL-positive cells in the spleen of mice treated with a dose of $100 \mathrm{mg}$ IOLE/ $\mathrm{kg}$ (Figures 4 and 5). However, the spleen of mice treated either with 200 or $300 \mathrm{mg}$ IOLE/kg showed no significant difference in the number of TUNEL-positive cells compared to the infected group (Figure 5).

To detect possible molecular changes induced in the spleens by $P$. chabaudi infections, we compared spleen gene expression in noninfected control mice with that of mice infected with $P$. chabaudi on day 7 pi, and we also compared infected mice with mice treated with $100 \mathrm{mg}$ IOLE $/ \mathrm{kg}$ after infection. Specifically, we isolated the total RNA from the individual spleens of five mice in each group, and pooled equal amounts of RNA before subjecting the samples to Agilent 2-color microarray analysis. Among the total 55,680 oligo spots on the microarray, 4,037 spots were upregulated and 3,126 spots were downregulated (comparing the microarray of the infected group with that of the infected treated group) (Figure S1A). We also categorized the genes according to function into: immune response genes and genes concerned with metabolism, signaling, transport, gene expression, and erythrocytes function (Figure S1B). In this article, we concentrate only on those genes that are related to immune response, with their expressions being altered by more than twofold. It is clear from our data that IOLE was able to upregulate six genes (Table 2) and downregulate 24 genes (Table 3 ).

Among the differentially up- and downregulated genes under IOLE, we quantified the expression of four genes (Ccl8, Saa3, Cd209a, and Cd209b). The expression data determined by microarrays were largely consistent with the expression analyses we performed with several arbitrarily selected genes using quantitative PCR (Figure 6).

\section{Discussion}

Our previous studies revealed that clearance of malarial parasites appears to be mediated by both acquired and innate immune responses. ${ }^{13-15}$ Also, female C57BL/6 mice were able to heal infections with $P$. chabaudi and develop long lasting immunity against homologous rechallenge. ${ }^{13}$ I. oblongifolia extract was able to significantly lower the infection-induced parasitemia. This may be due to the presence of the active compounds of I. oblongifolia, such as saponins (steroids or triterpenes), phenol, quinines, and coumarin. ${ }^{16}$ 

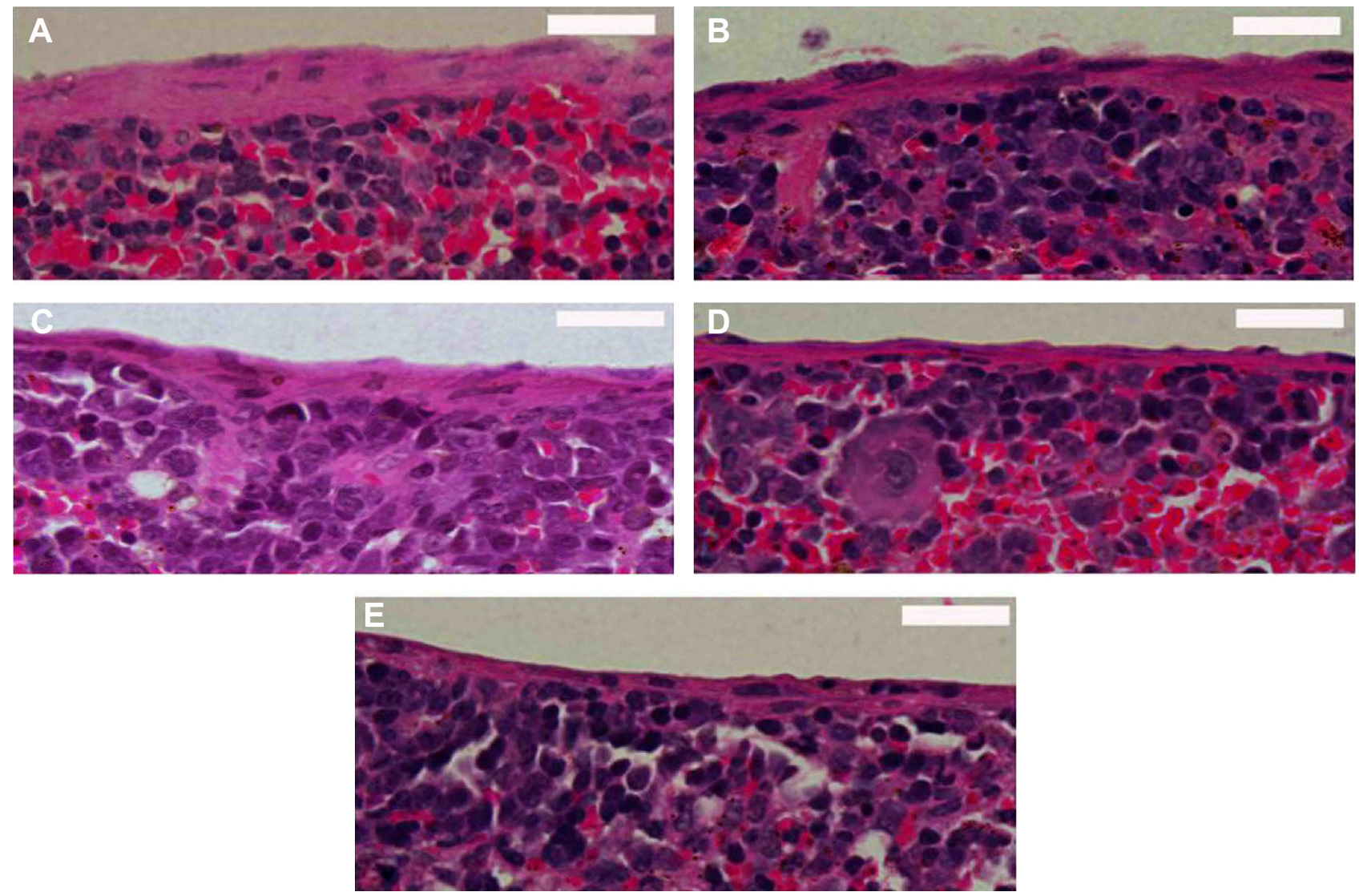

Figure 2 Indigofera oblongifolia-induced changes in mouse spleen capsules infected with Plasmodiun chabaudi at day 7 pi.

Notes: (A) Noninfected spleen with normal capsule. (B) Infected spleen with thin capsule. (C) Infected I. oblongifolia treated (100 mg/kg) spleen with moderate thickness. (D) Infected I. oblongifolia treated $(200 \mathrm{mg} / \mathrm{kg}$ ) spleen with more thickened capsule. (E) Infected I. oblongifolia treated (300 mg/kg) spleen with thickened capsule. Sections are stained with hematoxylin and eosin. Scale bar $=25 \mu \mathrm{m}$.

Abbreviation: pi, postinfection.

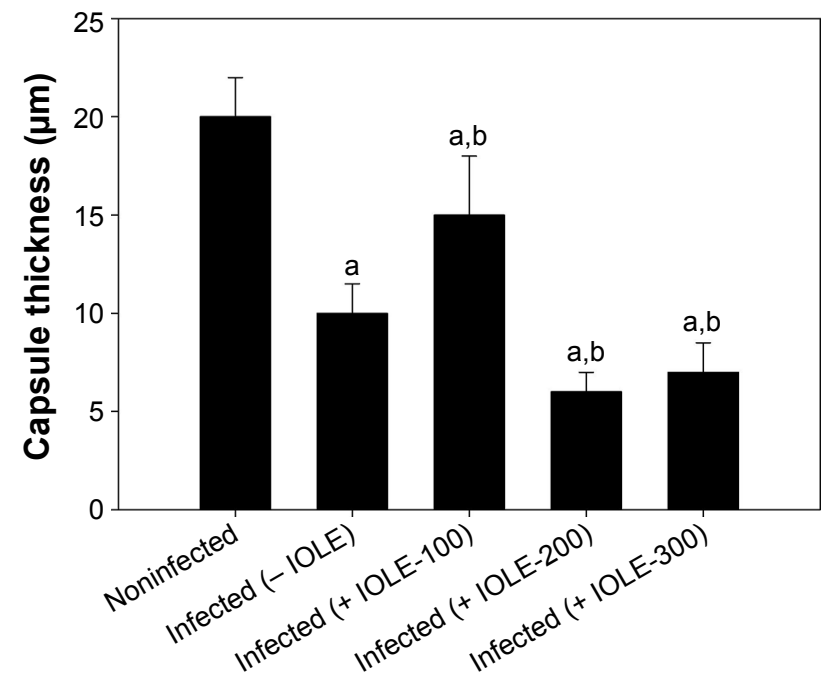

Figure 3 Changes in capsule thickness of spleens of uninfected, Plasmodiun chabaudiinfected, and infected $I$. oblongifolia treated mice on day 7 pi.

Notes: Values are means \pm SD. aSignificant against noninfected group at $P \leq 0.05$. bSignificant against infected (- IOLE) group at $P \leq 0.05$.

Abbreviations: pi, postinfection; SD, standard deviation; IOLE, I. oblongifolia leaf extract.
The differentiation of the spleen to an antimalarial effector organ is associated with splenomegaly and reorganizations of the spleen at maximal parasitemia. ${ }^{17}$ The change in spleen thickness during malaria has been reported in many studies and may be due to stretching of splenic parenchyma. ${ }^{18-20}$ There is an apparent enlargement of white pulp areas preceding the disappearance of white and red pulp segregation. This coincides with an increase in the number of leukocytes. ${ }^{17}$ Also, Helmby et a ${ }^{21}$ reported that malarial infection is characterized by both major activation and suppression of the immune system during different phases of the disease. Our results support Khare's observation that all parts of the plant are used in treating enlargements of the liver and spleen. ${ }^{22}$

Apoptotic cells have been found in the spleen among macrophages, T cells, and B cells, as was increased Fas expression; this indicates that $P$. chabaudi-induced apoptosis is, at least in part, a Fas-mediated event. ${ }^{17,21}$ In our study, 

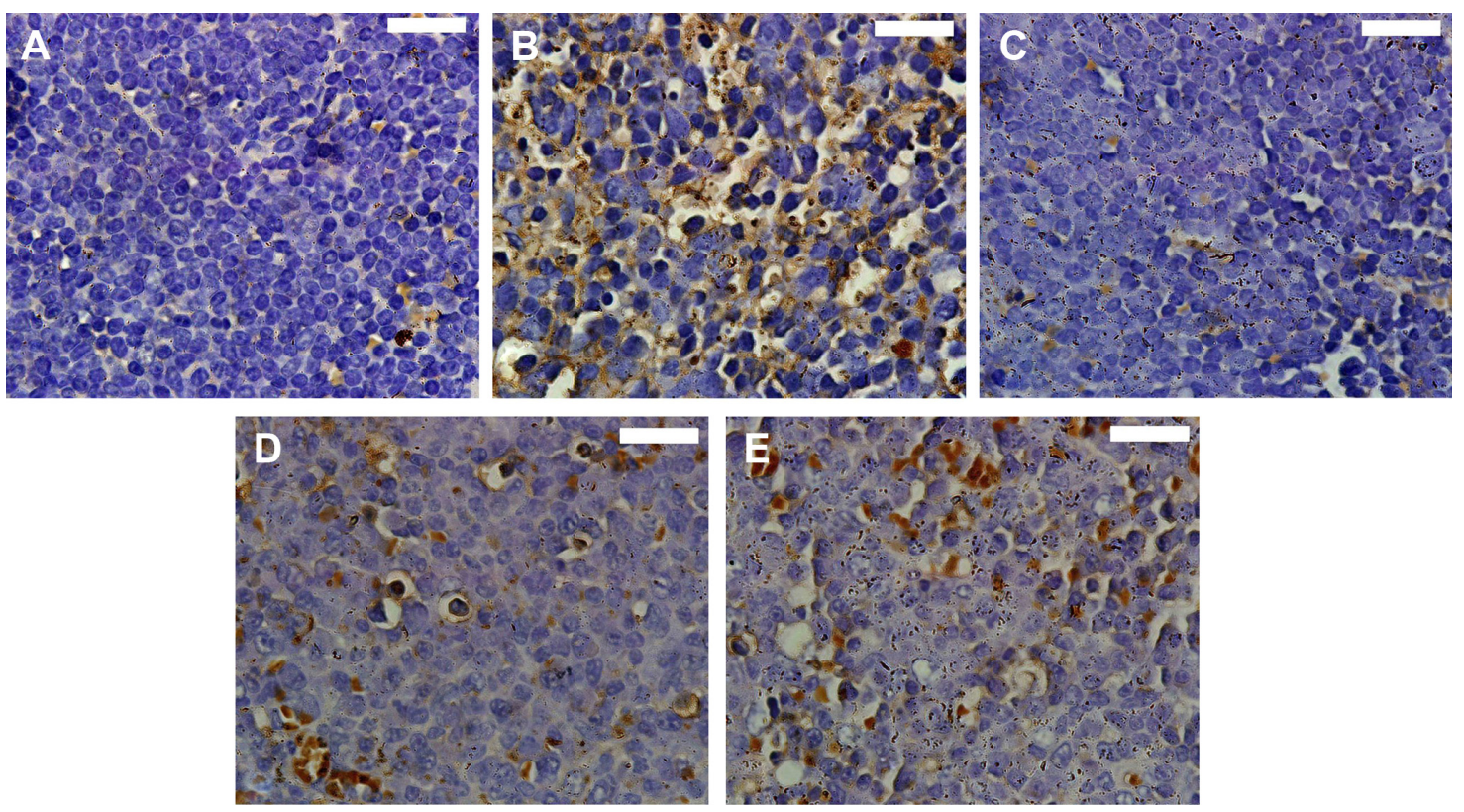

Figure 4 Indigofera oblongifolia-induced apoptotic changes in mouse spleens infected with Plasmodiun chabaudi at day 7 pi.

Notes: (A) Uninfected spleen. (B) Infected spleen. (C) Infected I. oblongifolia treated (I00 mg/kg) spleen. (D) Infected I. oblongifolia treated (200 mg/kg) spleen. (E) Infected I. oblongifolia treated $(300 \mathrm{mg} / \mathrm{kg})$ spleen. TUNEL-positive cells appeared brown. Scale bar $=25 \mu \mathrm{m}$.

Abbreviations: TUNEL, terminal deoxynucleotidyl-transferase-mediated dUTP nick end labeling assay; pi, postinfection.

IOLE could significantly decrease the infection-induced apoptosis in the mice spleen.

The antimalarial activities of I. oblongifolia are associated with changes of gene expression induced by parasites in the P. chabaudi-infected mouse spleen. In particular, it is remarkable that I. oblongifolia upregulates, by more than twofold, the mRNA expression of genes encoding a

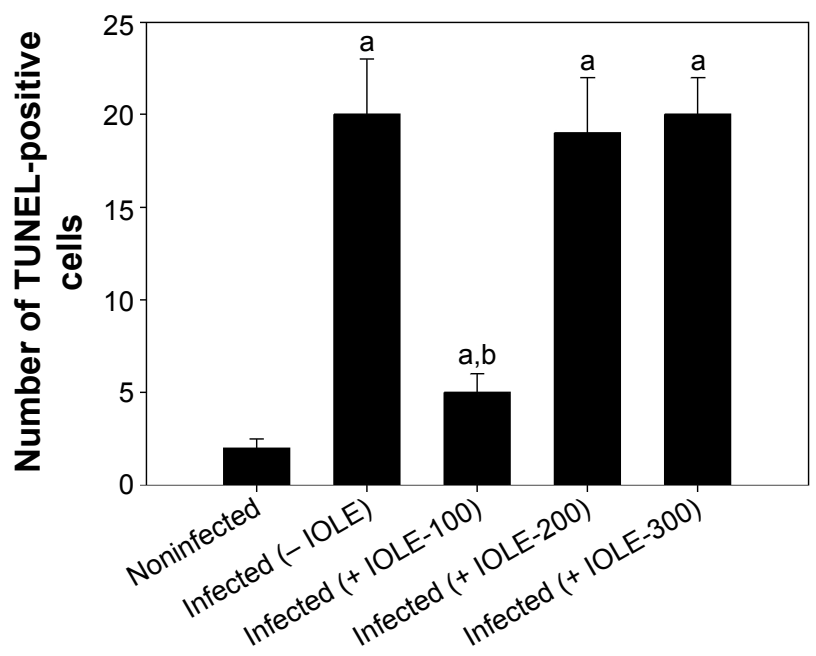

Figure 5 Indigofera oblongifolia-induced changes in the number of TUNEL-positive cells in spleens of mice infected with Plasmodium chabaudi on day 7 pi.

Notes: Results were expressed as the total positive numbers from 10 random and continuous fields from each section. Values are means \pm SD. a Significant against noninfected group at $P \leq 0.05$. 'Significant against infected (- IOLE) group at $P \leq 0.05$.

Abbreviations: pi, postinfection; TUNEL, terminal deoxynucleotidyl-transferasemediated dUTP nick end labeling assay; SD, standard deviation; IOLE, I. oblongifolia leaf extract. transmembrane receptor (Cd209a, Cd209b, Cd209d, and Cd209e). These genes are often referred to as DC-SIGN because of their expression on the surface of dendritic cells and macrophages. The encoded proteins are involved in the innate immune system and recognize divergent pathogens ranging from parasites to viruses. ${ }^{23}$

Also, I. oblongifolia affects expression of the genes $\mathrm{Cr} 2$ and Fcer2a, which code for B-lymphocyte activation. ${ }^{24}$ In addition, Timd 4 in the spleen was upregulated after treatment with I. oblongifolia. This gene enhances the engulfment of apoptotic cells and is also involved in regulating T-cell proliferation and lymphotoxin signaling. ${ }^{25}$ The chemokine (C-C motif) ligand 8 (Ccl8) was also highly expressed. This gene is located on chromosome 17 and is responsible for the immunoregulatory and inflammatory processes. ${ }^{26}$ P. chabaudi was able to upregulate the expression of $\mathrm{Ccl}$. This cytokine displays chemotactic activity for monocytes, lymphocytes, basophils, and eosinophils, and is responsible for immunoregulatory and inflammatory processes, ${ }^{26}$ but I. oblongifolia was able to downregulate the expression of this gene.

Finally, I. oblongifolia was able to alter the expression of Saa3 from 34-fold to 3.5-fold. Zhang et $\mathrm{al}^{27}$ reported that this gene is highly expressed during infection and its transcription is induced in many organs, including the spleen.

Collectively, I. oblongifolia has antimalarial activity and can protect the spleen from $P$. chabaudi-induced injury. 


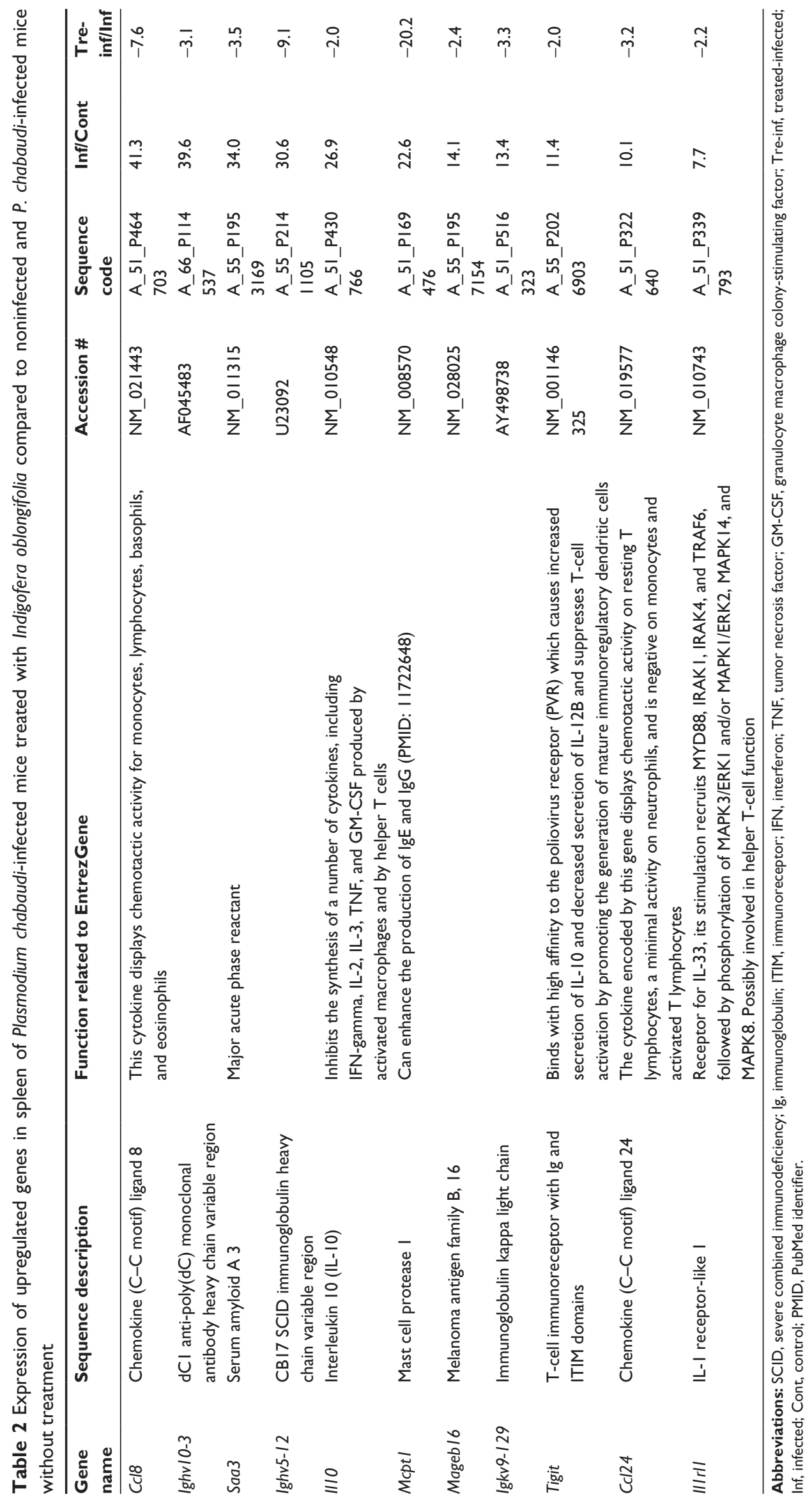




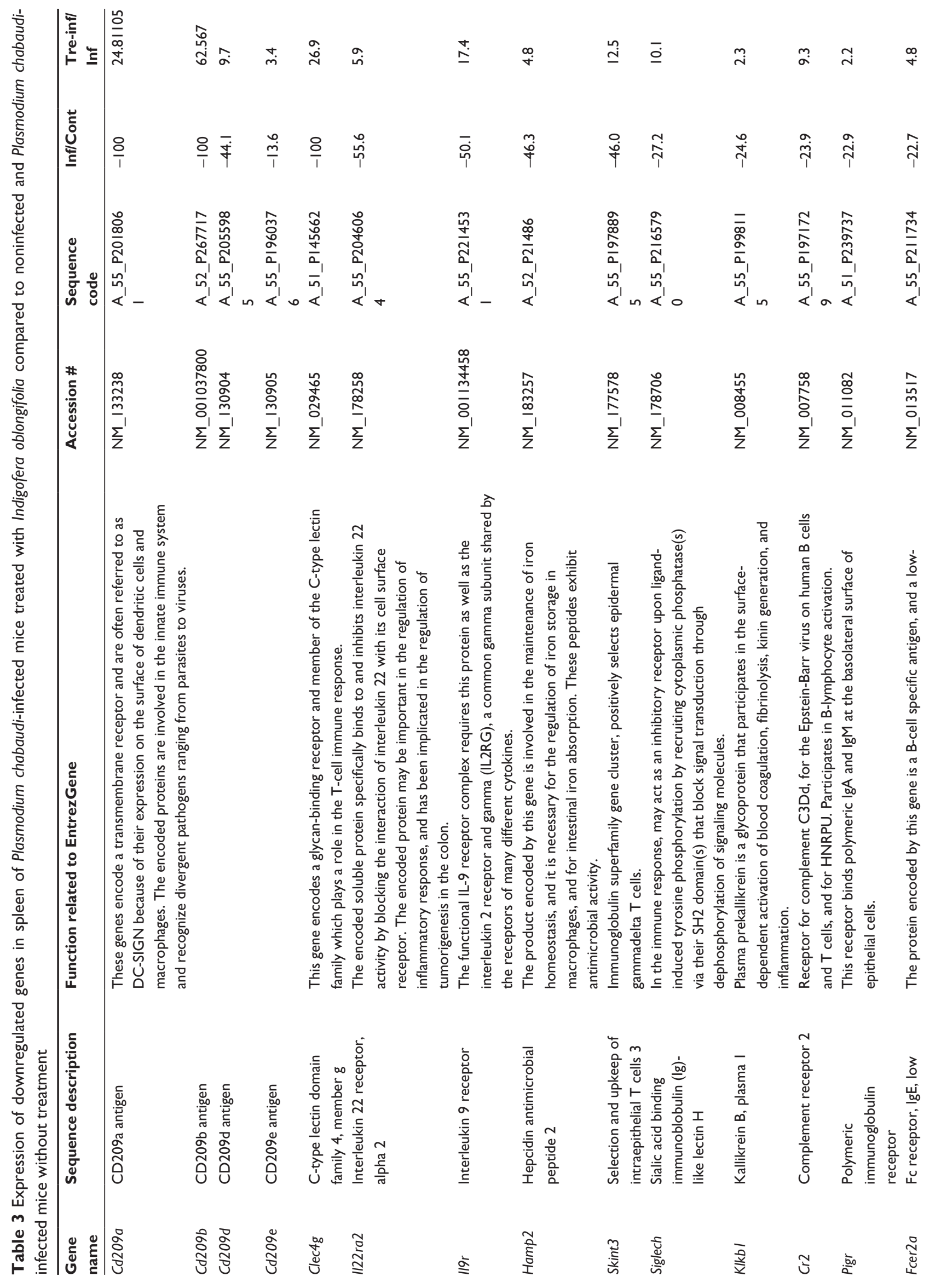




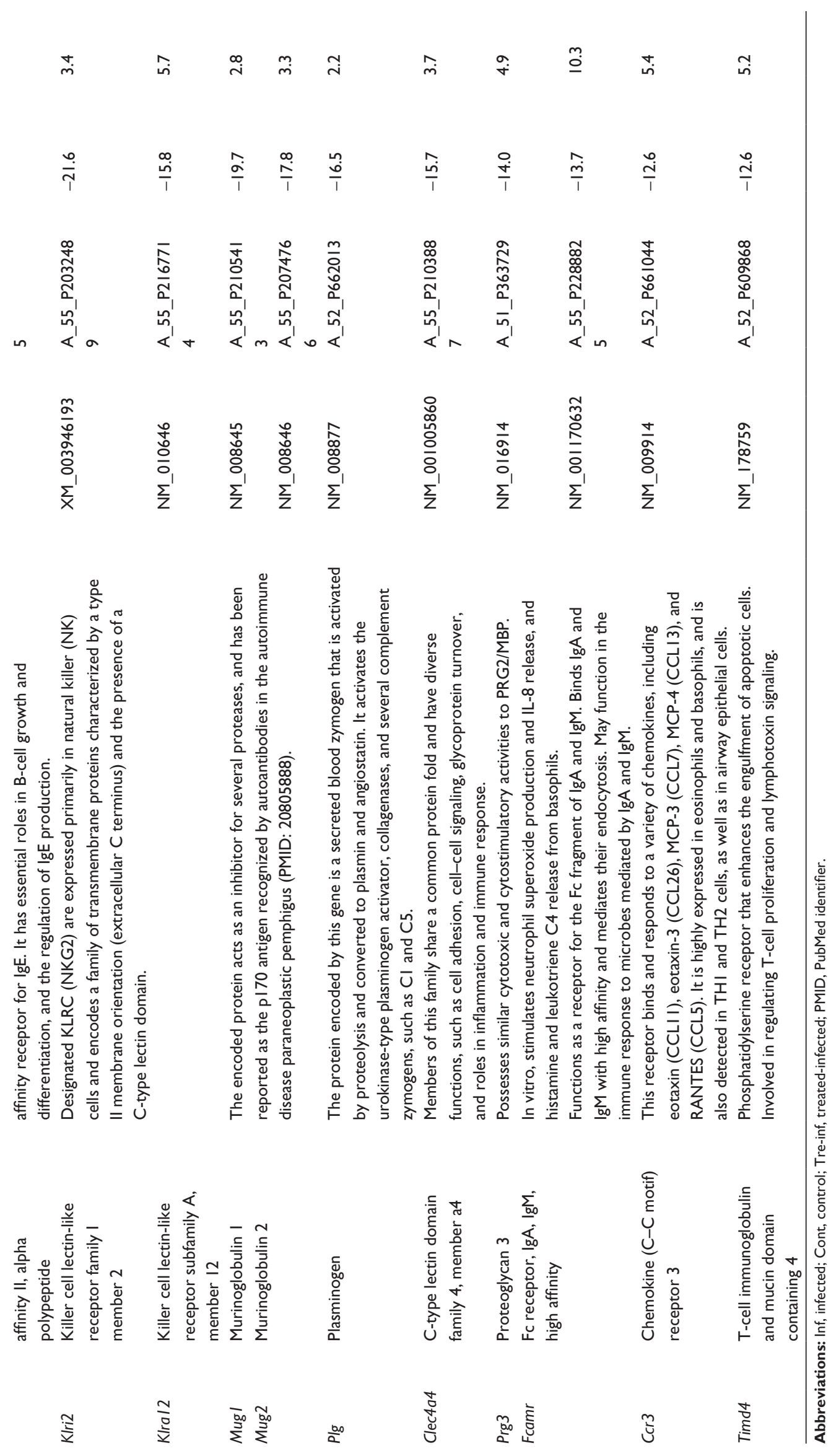




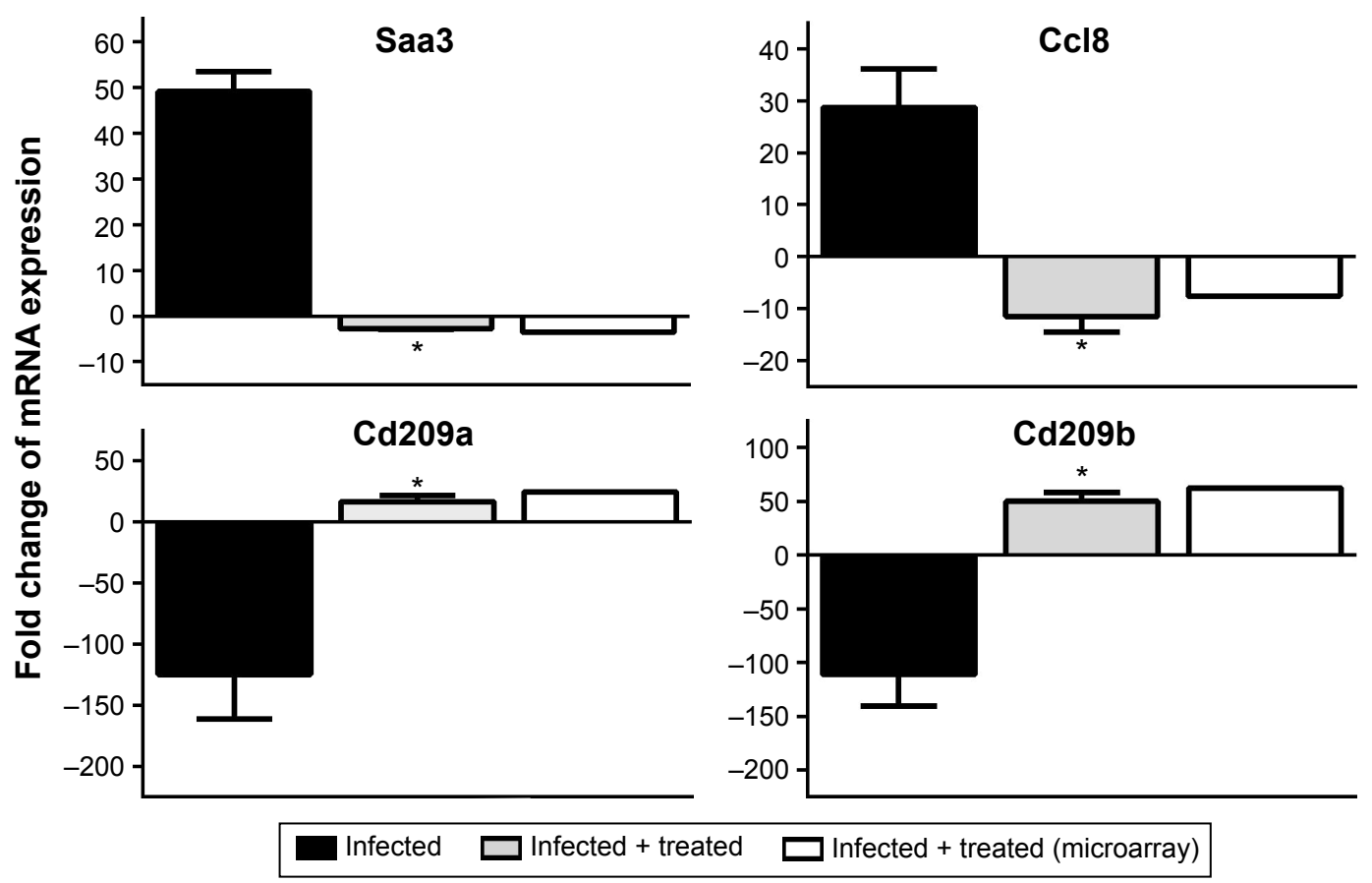

Figure 6 Expression of selected genes determined by quantitative RT-PCR and microarray analysis.

Notes: Quantitative RT-PCR of SAA3, CCL8, CD209A, and CD209B in the spleens of mice infected with Plasmodium chabaudi was performed. Expression of mRNAs was determined in spleens from uninfected and infected mice on day $7 \mathrm{pi}$, normalized to GAPDH mRNA expression, and relative expression is given as fold change compared to the uninfected control mice. *Significant against infected (- IOLE) group at $P \leq 0.05$.

Abbreviations: RT-PCR, reverse transcription polymerase chain reaction; GAPDH, glyceraldehyd-3-phosphate-dehydrogenase; pi, postinfection.

Further studies are required to evaluate the mechanism of I. oblongifolia action as well as the effect of active components in the plant extract.

\section{Acknowledgment}

The authors extend their appreciation to the Deanship of Scientific Research at King Saud University for funding the work through the research group project No PRG-1436-02.

\section{Author contributions}

All authors contributed toward data analysis, drafting, and critically revising the paper and agree to be accountable for all aspects of the work.

\section{Disclosure}

The authors report no conflicts of interest in this work. The authors alone are responsible for the content and writing of this paper.

\section{References}

1. Mehlhorn H, editor. Encyclopedic Reference of Parasitology, Vol 1. 4th ed. Berlin: Springer; 2014.

2. WHO. World Malaria Report. Geneva: World Health Organization, 2010.

3. Klein EY. Antimalarial drug resistance: a review of the biology and strategies to delay emergence and spread. Int J Antimicrob Agents. 2013;41: 311-317.
4. Petersen I, Eastman R, Lanzer M. Drug-resistant malaria: molecular mechanisms and implications for public health. FEBS Lett. 2011; 585(11):1551-1562.

5. Nzila A, Al-Zahrani I. Drugs for the treatment of malaria in the Kingdom of Saudi Arabia. Saudi Med J. 2013;34(6):569-578.

6. Al-Adhroey AH, Nor ZM, Al-Mekhlafi HM, Amran AA, Mahmud R. Antimalarial activity of methanolic leaf extract of Piper betl L. Molecules. 2010;16(1):107-118.

7. Mubaraki MA, Dkhil MA, Al-Shaebi EM, Lubbad MY, Ibrahim KE, Al-Quraishy S. The protective effect of pomegranate, Punica granatum, on murine malaria. Pak J Zool. 2014;46:1345-1350.

8. Taherkhani M, Rustaiyan A, Nahrevanian H, Naeimi S, Taherkhani T. Comparison of antimalarial activity of Artemisia turanica extract with current drugs in vivo. J Vector Borne Dis. 2013;50(1):51-56.

9. Lubbad MY, Al-Quraishy S, Dkhil MA. Antimalarial and antioxidant activities of Indigofera oblongifolia on Plasmodium chabaudiinduced spleen tissue injury in mice. Parasitol Res. 2015;114(9): 3431-3438.

10. Wunderlich F, Stübig H, Königk E. Development of Plasmodium chabaudi in mouse red blood cells: structural properties of the host and parasite membranes. J Protozool. 1982;29:60-66.

11. Drury RAB, Wallington EA. Carleton's Histological Technique. 5th ed. Oxford, UK: Oxford University Press; 1980:188-189, 237-240, 290-291.

12. Delic D, Gailus N, Vohr HW, Dkhil M, Al-Quraishy S, Wunderlich F. Testosterone-induced permanent changes of hepatic gene expression in female mice sustained during Plasmodium chabaudi malaria infection. J Mol Endocrinol. 2010;45:379-390.

13. Krücken J, Mehnert LI, Dkhil MA, et al. Massive destruction of malaria parasitized red blood cells despite spleen closure. Infect Immun. 2005;73:6390-6398.

14. Dkhil MA. Apoptotic changes induced in mice splenic tissue due to malaria infection. J Microbiol Immunol Infect. 2009;42:13-18. 
15. Wunderlich F, Al-Quraishy S, Steinbrenner H, Sies H, Dkhil MA. Towards identifying novel anti-Eimeria agents: trace elements, vitamins, and plant-based natural products. Parasitol Res. 2014;113: 3547-3556.

16. Shahjahan M, Vani G, Shyamala-Devi CS. Protective effect of Indigofera oblongifolia in CCl4-induced hepatotoxicity. J Med Food. 2005; 8:261-265.

17. Wunderlich F, Dkhil MA, Mehnert LI, et al. Testosterone-responsiveness of spleen and liver in female lymphotoxin-beta receptor-deficient mice resistant to blood stage malaria. Microbes Infect. 2005;7:399-409.

18. Mokashi AJ, Shirahatti RG, Prabhu SK, Vagholkar KR. Pathological rupture of malarial spleen. J Postgrad Med. 1992;38:141-142.

19. Machado Siqueira A, Lopes Magalhães BM, Cardoso Melo G, et al. Spleen rupture in a case of untreated Plasmodium vivax infection. Franco-Paredes C, ed. PLoS Neglected Tropical Diseases. 2012;6(12): e1934.

20. Dkhil MA, Al-Quraishy S, Al-Shamrany A, et al. Protective effect of berberine chloride on Plasmodium chabaudi-induced hepatic tissue injury in mice. Saudi J Biol Sci. 2015;22(5):551-555.
21. Helmby H, Jönsson G. Troye-Blomberg M. Cellular changes and apoptosis in the spleens and peripheral blood of mice infected with blood-stage Plasmodium chabaudi chabaudi AS. Infect Immun. 2000;68:1485-1490.

22. Khare CP. Indian Medicinal Plants: An Illustrated Dictionary. SpringerVerlag New York; 2007.

23. McGreal E, Miller J, Gordon S. Ligand recognition by antigen-presenting cell C-type lectin receptors. Curr Opin Immunol. 2005;17:18-24.

24. Bohnsack J, Cooper NR. CR2 ligands modulate human B cell activation. J Immunol. 1988;141(8):2569-2576.

25. Ji H, Liu Y, Zhang Y, et al. T-cell immunoglobulin and mucin domain 4 (TIM-4) signaling in innate immune-mediated liver ischemiareperfusion injury. Hepatology. 2014;60(6):2052-2064.

26. Proost P, Wuyts A, Van Damme J. Human monocyte chemotactic proteins-2 and -3: structural and functional comparison with MCP-1. J Leukoc Biol. 1996;59:67-74.

27. Zhang N, Ahsan MH, Purchio AF, West DB. Serum amyloid A-luciferase transgenic mice: response to sepsis, acute arthritis, and contact hypersensitivity and the effects of proteasome inhibition. J Immunol. 2005; 174:8125-8134. 


\section{Supplementary material}

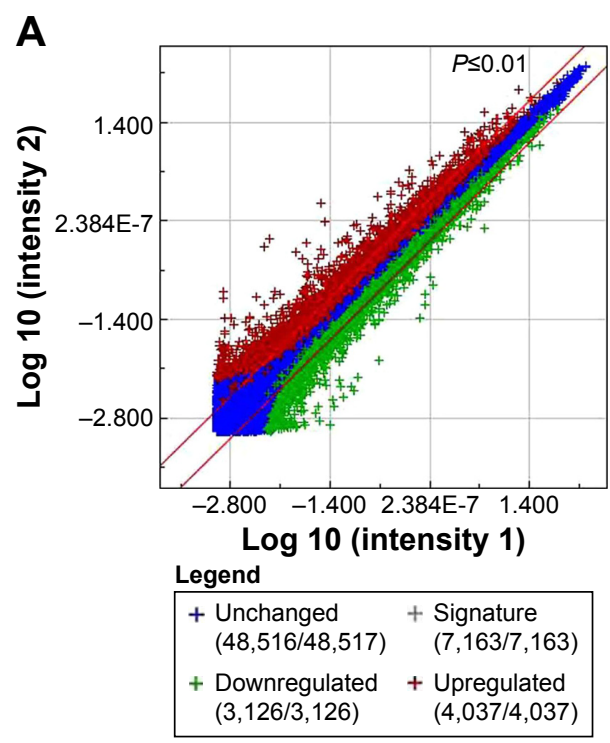

\section{B}

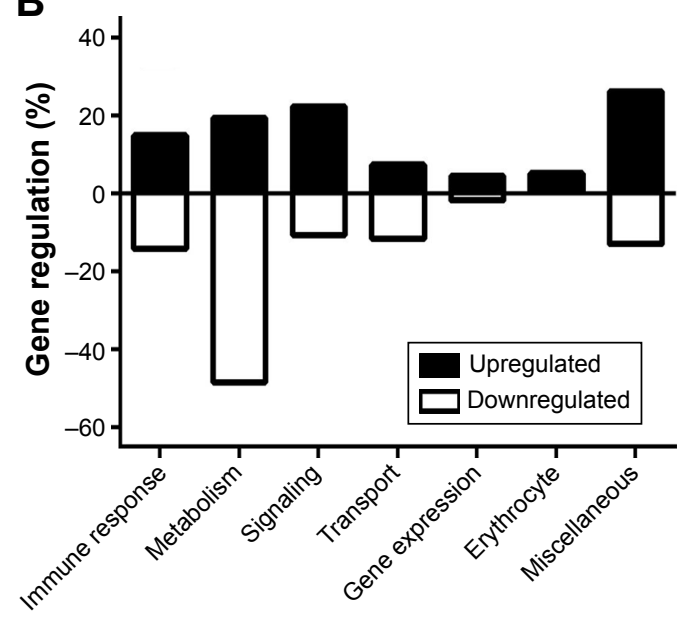

Figure SI Gene expression in spleens of Plasmodium chabaudi-infected mice treated with Indigofera oblongifolia leaf extract.

Notes: (A) Scatter plot of signal intensities of all spots. As an example, the data of one array experiment is shown. The signal intensities of each feature represented by a dot are shown in double logarithmic scale. X-axis: control-log signal intensity; Y-axis: sample-log signal intensity. Red diagonal lines define the areas of twofold differential signal intensities. Blue cross: unchanged genes; red cross: significantly upregulated genes $(P$-value $<0.0 \mathrm{I})$; green cross: significantly downregulated genes $(P$-value $<0.0 \mathrm{I})$; gray cross in legend: summary of significantly up- and downregulated signatures. (B) Summary of percentage change in gene regulation according to function. Data for Plasmodium chabaudi-infected vs infected-treated (+ IOLE-100) spleen.

Abbreviation: IOLE, I. oblongifolia leaf extract.

\section{Publish your work in this journal}

Drug Design, Development and Therapy is an international, peerreviewed open-access journal that spans the spectrum of drug design and development through to clinical applications. Clinical outcomes, patient safety, and programs for the development and effective, safe, and sustained use of medicines are a feature of the journal, which has also been accepted for indexing on PubMed Central. The manuscript management system is completely online and includes a very quick and fair peer-review system, which is all easy to use. Visit http://www.dovepress.com/testimonials.php to read real quotes from published authors. 